\title{
Thrombosis-Related Factors FV and F13A1 Mutations in Uterine
}

\section{Myomas}

\author{
Marzieh Ahmadi, ${ }^{1}$ Mahboobeh Nasiri,," and Ahmad Ebrahimi ${ }^{2}$ \\ ${ }^{1}$ Department of Biology, Islamic Azad University, Arsanjan Branch, Arsanjan, IR Iran \\ ${ }^{2}$ Cellular and Molecular Research Center, Research Institute for Endocrine Sciences, Shahid Beheshti University of Medical Sciences, Tehran, IR Iran \\ "Corresponding author: Mahboobeh Nasiri, Department of Biology, Islamic Azad University, Arsanjan Branch, Arsanjan, IR Iran. Tel: +98-9173010601, E-mail: nasiri@iaua.ac.ir
}

Received 2015 November 28; Revised 2015 December 26; Accepted 2016 September 24.

\begin{abstract}
Background: Uterine myoma is a common benign, solid tumor in women with reproductive age. Thrombosis factors play a major role in tumor formation and also tumors induce thrombotic processes. Factor V (FV) and factor 13A1 (F13A1) are two thrombotic factors, which their dysfunctions affect the clot formation. FV Leiden, a common mutation in F5 gene, and V34L mutation in F13A1 gene are known to affect the risk of thrombosis. The purpose of the present study was to determine the possible association of FV Leiden and F13A1 Valine to Leucine at codon 34 (Val34Leu) mutations with the risk of developing uterine myoma in the women from south of Iran.

Methods: In this case-control study, FV Leiden and V34L mutations were genotyped in 73 myoma patients and 73 healthy subjects using amplification refractory mutation system-polymerase chain reaction (ARMS-PCR). The data were analyzed by logistic regression, $\chi 2$ test and SPSS software version 16.0.

Results: Regarding the results, only F13A1 V34L mutation was associated with myoma. The Val allele showed the protective role on myoma among the studied population (OR: 0.49, 95\% CI: $0.24-1, \mathrm{P}=0.05$ ). In addition, we found that individuals with F13A1 V/V (OR: 0.09, 95\% CI: $0.005-1.8, \mathrm{P}=0.04)$ and V/L (OR: 0.1, 95\% CI: $0.006-1.98, \mathrm{P}=0.042)$ genotypes had a significantly lower risk of myoma tumor compared with the other genotype $(\mathrm{L} / \mathrm{L})$. Moreover, there was no association between $\mathrm{V} 34 \mathrm{~L}$ mutation and myoma after adjusting the data for the factor age $(\mathrm{P}>0.05)$.
\end{abstract}

Conclusions: Our results introduce the F13A1 V34L mutation as an age-related risk factor for myoma.

Keywords: Uterine Myoma, Thrombosis, F13A1 V34L, FV Leiden

\section{Background}

Uterine myomas (fibroids) are benign tumors originated from smooth muscle of the uterus. Myomas are typically found in $20 \%-40 \%$ of females at reproductive age [1]. Given the heterogeneous nature of the disease, many genes are suggested to be involved in its pathogenesis, though much work is required to determine the molecular biology of these tumorigenesis [2]. Many thrombotic processes are activated by tumors, on the other hand, clot formation could protect tumor cells from the immune system in some stage of the tumorigenesis [3]. Because of the dependency of tumor growth to thrombosis, coagulation factors could be considered as a major risk factor in tumorigenesis $[3,4]$. Several studies have investigated the role of thrombosis factors in tumors and have shown the importance of thrombosis management in tumor treatment [5, 6]. Although the coincidence of myoma and thrombosis is reported in several types of research $[7,8]$, published studies on the association between myoma and thrombosis- related mutations are limited. FXIII and FV are two important coagulation factors, which their deficiencies cause severe thrombotic disorders $[9,10]$.

FXIII is the last zymogen in the coagulation cascade, which consists of two non-covalently related subunits: A subunit is coded by F13A1 gene that is responsible for its catalytic activity and "B" subunit acts as a molecular carrier in plasma [11]. F13A1 gene has been mapped on chromosome $6 \mathrm{p} 24-25$, which spans $160 \mathrm{~kb}$ of the genome [12]. The protein products of this gene covalently cross-link the fibrin clot to increase resistance to proteolytic insults [13]. Valin ( $G$ allele) to Leucine ( $\mathrm{T}$ allele) substitution at codon 34 in exon 2 of the F13A1 gene is known as a common mutation in this gene [14].

V34L mutation locates adjacent to the thrombin cleavage site of FXIII and results in a faster activation of F XIII by thrombin [15]. Then, this variant increases the resistance to clot formation and could decrease thrombosis risk [14].

Factor $\mathrm{V}$ is the other essential coagulation component required for normal clotting cascade. The gene for factor $\mathrm{V}$ 
is localized on chromosome 1q24.2 [16]. Activated thrombosis factor 5 (FV) forms a complex with Factor X, which in turn changes fibrinogen to fibrin. The most prevalent mutation in the F5 gene called FV Leiden (FVL, rs6025), occurred exactly at the cleavage site for activator protein $\mathrm{C}$ (APC). Consequently, the FV Leiden is resistant to APC and remains active and increases the rate of thrombin generation [17]. This mutation is associated with G-to-A substitution in exon 10 of F5 gene, which results in Arginine (Arg) to Glutamine (Gln) change at codon 506 (R506Q) [18].

In this study, we aimed to investigate the association of two genetic mutations, rs5985 (V34L) in A subunit of F13A1 gene and rs6025 (FVL) in F5 gene and the risk of myoma in women from the south of Iran.

\section{Methods}

\subsection{Study Population}

In total, 73 diagnosed women with uterine myomas with the age range $29-65$ years (mean $\pm S D, 50.5 \pm 7$ years), and 73 healthy women (16 - 51 years, $38.4 \pm 7$ years) as control subjects were enrolled in this case- control study. Patients subdivided into three categories based on the age. The age range from 21 - 30 years old (12 cases: 16.4\%), 31 40 years old (27 cases: $37 \%$ ) and 41 - 50 years old (34 cases: 46.6\%). Blood samples were provided by Hazrat-e-Zeynab hospital, Shiraz, Iran. Patients who their uterine myoma confirmed by laparoscopy were signed the informed consent. The inclusion criteria were: a, symptomatic uterine myoma; and b, indication for surgery (hysteroscopy or myomectomy). Exclusion criteria: a, pregnancy; b, breastfeeding; c, hormonal contraception or any hormonal therapy in the last 3 months; d, any genital tumors and e, unexplained genital bleeding. All clinical procedures were approved by the local Ethics Committee of Shiraz Medical School.

\subsection{Genotyping}

DNA from venous blood was isolated using the phenolchloroform method and used for genetic analysis [19]. Two mutations, including FVL (rs6025) in F5 gene and rs5985 in F13A1 gene, were genotyped using amplification refractory mutation system-polymerase chain reaction (ARMS-PCR) technique. Two PCR reactions were done for each individual, each with the allele specific primer, common primer and a pair of primer for a gene as an internal control. In the present study, the gene for Hemoglobin gamma 1 (HBG1) was selected to amplify as an internal control. Primers for two variations were designed using gene runner software. Details including the location of each mutation in the respective genes, primer sequences, annealing temperature and product sizes are presented in Tables 1 and 2. The reaction details are as follows: Both mutations were determined by ARMS-PCR using a Bio-Rad t100 thermo cycler with a total volume of $25 \mu \mathrm{L}$, containing PCR buffer: 1x, $\mathrm{MgCl}_{2}$ : $1.6 \mathrm{mM}$, Primers: $0.3 \mathrm{pM}$, dNTPs: $0.8 \mathrm{mM}$, Taq DNA polymerase: $2 \mathrm{U} / 25 \mu \mathrm{L}$, DNA: $200 \mathrm{ng} / 25 \mu$. The reaction condition for FVL mutation was: initial denaturation at $94^{\circ} \mathrm{C}$ for 5 minutes, followed by 30 cycles of denaturation at $94^{\circ} \mathrm{C}$ for $30 \mathrm{~s}$, annealing at $59^{\circ} \mathrm{C}$ for 50 seconds and extension at $72^{\circ} \mathrm{C}$ for 30 seconds, and a final extension step at $72^{\circ} \mathrm{C}$ for 5 minutes. The amplification condition for The F13A1 V34L polymorphism was: initial denaturation at $94^{\circ} \mathrm{C}$ for 5 minutes followed by 30 cycles of denaturation at $94^{\circ} \mathrm{C}$ for 30 seconds, annealing at $57^{\circ} \mathrm{C}$ for 45 seconds and extension at $72^{\circ} \mathrm{C}$ for 30 seconds, ended by a final extension at $72^{\circ} \mathrm{C}$ for 3 minutes. Amplified fragments were separated by $2 \%$ agarose gel electrophoresis stained with SYBER gold safe stain and visualized with a Light Transilluminator. DNA molecular weight marker (Fermentas, 50 bp Ladder) was used to assess the size of the PCR products.

\subsection{Statistical Analysis}

Quantitative data were expressed as a mean \pm standard deviation (SD). Differences categorical variables were presented using frequency counts and compared with a logistic regression test. Deviation from Hardy-Weinberg equilibrium was analyzed by a $\chi^{2}$ test. Odds ratio (OR) and $95 \%$ confidence interval $(\mathrm{CI})$ were calculated as an estimate of risk. $\mathrm{P}<0.05$ was considered statistically significant. All statistical analyses were performed with SPSS 16.0 software.

\section{Results}

We investigated two mutations, rs5985, and rs6025 in 73 patients with myoma and 73 healthy individuals. The schematic representations of Agarose gel electrophoresis for mutation analysis are shown in Figures 1 and 2. The internal control band was $546 \mathrm{bp}$ in length, but the allele specific products for the FV Leiden and FXIII V34L mutations were $152 \mathrm{bp}$ and $147 \mathrm{bp}$, respectively.

Our data showed that the risk of myoma tumor and age are in a direct relationship $(\mathrm{P}<0.05)$. Genotyping of the FV rs6025 mutation results in a surprising data in our studied population. Nearly all subjects (except one myoma patient) showed wild-type homozygote genotype (patient: controls; 98.6\% vs. 100\%, GG genotype). Regarding this homozygosity, no more statistical analysis was done for any association between this mutation and uterine myoma. As the data in Table 3 shows, the frequency of the wild-type Val 
Table 1. Mutations in F5 and F13A1 Genes, Their Locations, Primer Sequences, Annealing Temperatures and Product Sizes

\begin{tabular}{|c|c|c|c|}
\hline Gene & Mutation & Primer Sequence Temp & Annealing \\
\hline \multirow{3}{*}{ F5 } & \multirow{3}{*}{ FV Leiden, G/A, Exon 10} & Rv common: GGACTACTTGACAATTACTGTTCTCTTG & \multirow{3}{*}{$59^{\circ} \mathrm{C}$} \\
\hline & & Fw (G): GCAGATCCCTGGACAGACG & \\
\hline & & Fw (A): GCAGATCCCTGGACAGACA & \\
\hline \multirow{3}{*}{ F13 } & \multirow{3}{*}{ V34L, G/T, Exon 2} & Rv common: GAACCCCAGTGGAGACAGAG & \multirow{3}{*}{$57^{\circ} \mathrm{C}$} \\
\hline & & Fw (G):ACAGTGGAGCTTCAGCGCG & \\
\hline & & Fw (T): ACAGTGGAGCTTCAGCGCT & \\
\hline
\end{tabular}

Table 2. Characteristics of the Internal Control HBG1 Gene Primers

\begin{tabular}{l|l|l|}
\hline \multirow{2}{*}{ Gene } & Primer Sequence & Annealing Temp \\
\hline \multirow{2}{*}{ HBG1 } & Fw: AACGGCTGACAAAAGAAGTCCTGG & $57^{\circ} \mathrm{C}$ \\
\cline { 2 - 3 } & Rv: TGCCAGGCACAGGGTCCTTCC & \\
\hline
\end{tabular}

Abbreviation: HBG1, Hemoglobin gamma 1.

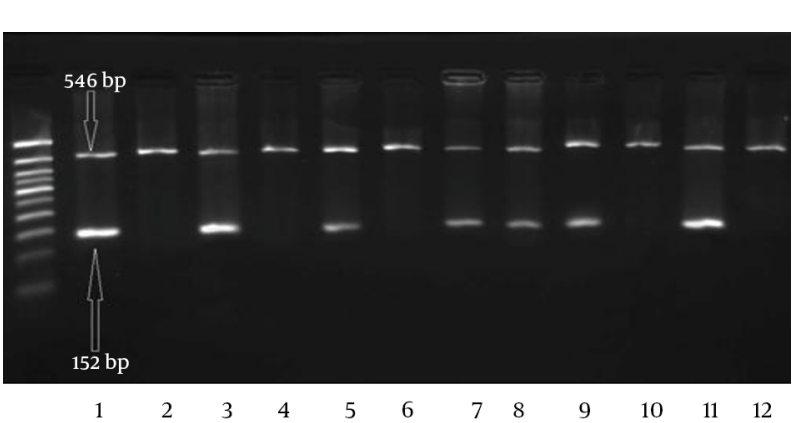

Figure 1. Agarose gel electrophoresis of the amplification products of FV Leiden mutation in F5 gene by ARMS-PCR. The first of each two well belongs to the normal primer for Arg allele ( $G$ allele), and the second is for the mutant allele Gln (A allele). Wells 1/2,3/4,5/6, 9/10 and 1//12 show the GG (Arg/Arg) genotype. Wells $7 / 8$ related to heterozygote genotype. The $50 \mathrm{bp}$ size marker is loaded in the first well.

allele (G allele) of the FXIII V34L mutation is $84 \%$ and $92 \%$ in cases and controls, respectively. This difference was statistically significant and showed the protective role on the risk of myoma development $(\mathrm{P}=0.05)$.

The possible association between FXIII V34L and myoma risk was estimated by calculating OR and 95\% CI (Table 3). The results showed the protective roles for the genotypes with at least one wild-type allele (Val/Val: GG or Val/Leu: GT genotype) compared with homozygous mutant genotype (Leu/Leu: TT) (OR: 0.1, 95\% CI: 0.006 - 1.98). After adjusting the genotype for age, no significant association was found between this mutation and myoma risks (OR: 1.2, 95\% CI: $0.41-3.5, \mathrm{P}=0.7$ ). The FXIII V34L genotype frequencies were in Hardy-Weinberg equilibrium ( $\mathrm{P}>$ 0.05).

\section{Discussion}

The results of our study showed that only F13A1 V34L mutation was associated with myoma. The Val allele showed the protective role on myoma among the studied population. Myomas are the most common benign tumors of woman's uterus with severe symptoms such as bleeding, pain and miscarriage as a consequent, thus, myoma is a significant health issue among women $[1,20]$. Age is considered as one of the risk factors for uterine myomas so that most diagnoses were recorded for women in their forties and above. The risk of myoma increases to more than $30 \%$ for women in this age range [21]. The results of the present study showed that $46.5 \%$ of the affected women were at the age higher than 40 years of old.

Myomas are the heterogeneous tumors with multifactorial inherent, so more than one specified class of gene expected to contribute to their development [22]. Dehraisi et al. (2015) published the data of their comprehensive investigation on the effect of Glutathione S-transferase (GST) gene polymorphisms (GSTM1, GSTT1 and GSTP1 genes) on the susceptibility to uterine myoma. All members of the GSTs gene family were reported as a risk factor for uterine myomas [23]. The result of the other study by Taghizade Mortezaee et al. (2015) introduced Interleukin- $\beta$ gene polymorphisms (IL-1 $\beta$-511 and IL-1 $\beta 3954$ ) as a probable risk factor for uterine myoma in Iranian patient women [24]. Salimi et al. (2014) also investigated the association between IL-4 VNTR polymorphism and the risk of developing uterine fibroid in about 100 Iranian women with uterine fibroid. They reported IL-4 PR2/PR2 genotype as an age- related risk factor for fibroid [25]. The results of the 


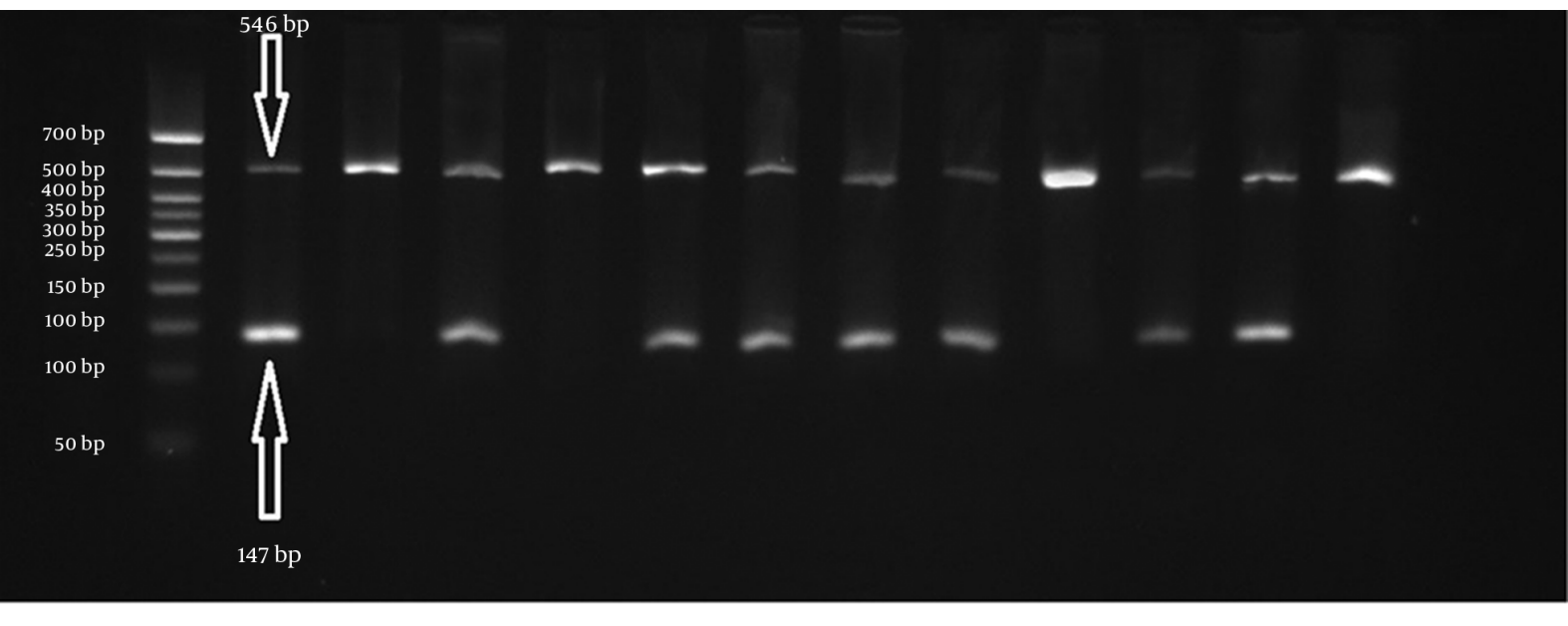

$\begin{array}{lllllllllll}1 & 2 & 3 & 4 & 5 & 6 & 7 & 8 & 9 & 10 & 11\end{array}$

Figure 2. Schematic representation of the agarose gel electrophoresis for the rs5985 polymorphism in F13A1 gene. The first wells of each two well are related to the normal primer for allele Val (G) and the second one is for the mutant primer for allele Leu(T). Wells 1/2,3/4,11/12 show the wild type homozygote genotype(GG; Val/Val). The heterozygote genotype is seen in $5 / 6$ and $7 / 8$ wells and the wells $9 / 10$ are related to mutant homozygote individual (TT; Leu/Leu). The first well from the left is the 50 bp size marker.

Table 3. Distribution of the F13 rs5985 Gene Mutations in Myoma Patients and Controls ${ }^{\mathrm{a}}$

\begin{tabular}{|c|c|c|c|c|c|c|}
\hline rs5985 & Myoma & Controls & OR $(95 \% \mathrm{CI})$ & $\mathbf{P}$ & $\mathrm{OR}(95 \% \mathrm{CI})^{\mathrm{b}}$ & $\mathbf{P}^{\mathbf{b}}$ \\
\hline Genotypes GG & $53(73)$ & $60(82)$ & $0.09(0.005-1.8)$ & 0.04 & - & 0.9 \\
\hline GT & $16(22)$ & $13(18)$ & $0.13(0.007-2.75)$ & 0.08 & $1.2(0.41-3.5)$ & 0.7 \\
\hline TT & $4(5)$ & $0(0)$ & 1 & - & 1 & - \\
\hline $\mathbf{G G}+\mathbf{G T}$ & $69(95)$ & $73(100)$ & $0.1(0.006-1.98)$ & 0.04 & & \\
\hline Alleles G & $122(84)$ & $133(92)$ & $0.49(0.24-1)$ & 0.05 & & \\
\hline $\mathbf{T}$ & $24(16)$ & $13(18)$ & 1 & - & & \\
\hline
\end{tabular}

Abbreviations: CI, confidence interval; OR, Odd ratio.

${ }^{\mathrm{a}}$ Values are expressed as No. (\%).

${ }^{\mathrm{b}}$ Adjusted for age.

two recent meta-analyses confirmed the involvement of CYP1A1 Ile462Val and HSD17B1 rs605059 polymorphisms in the pathobiology of uterine fibroids $[26,27]$.

Among all, the role of coagulation abnormalities, disturbance of fibrin formation and fibrinolysis, increased in clotting reaction by-products, protein $\mathrm{C}$ resistance and high levels of microparticles are the most questionable etiologies in tumor cells [28]. The correlation between thrombosis and tumorigenesis suggesting thrombosis factors as a good candidate for diagnosis and prognosis of tumor formation. Although coincidence between myoma and thrombosis have been reported in many cases $[10,29,30]$, to our knowledge, this is the first investigation of the relationship between myoma and thrombosisrelated mutations. There is some evidence of the involve- ment of thrombosis-related mutations in the establishment and progression of other tumors. For instance, the frequency of oral cancer increased in relation to the F13A1 V34L mutation [20]. FV Leiden is known as a causative genetic variation in gastrointestinal tumor and lymphoblastic leukemia [31, 32]. In the present study, no association was found between FV Leiden mutation and the risk of uterine myoma, as our studied population showed homozygosity for this mutation.

The results of our study regarding V34L mutation are consistent with the previous one. Franco et al. (1999) showed the protective effect of the homozygote state for V34L (V/V; GG) mutation against venous thrombosis and myocardial infarction, respectively [33]. the co-existence of V34L and MTHFR is reported in non-Hodgkin lymphoma 
[34] on the other hand, a study in Netherland showed a 15\% reduced the risk of colorectal cancer in the present of G allele in relation to V34L mutation [35].

In conclusion, the result of our study did not show any relationship between the FV Leiden mutation and uterine myoma. In contrast, the results suggest the protective role for the wild-type Val allele of the F13A1 V34L mutation, but it seems the results influenced by age. Further investigation may require to clear the importance of this polymorphism in the diagnosis and prognosis of myoma.

\section{Acknowledgments}

The data were extracted from the thesis association assessment between FV(rs1801133) and F13A1 (rs867186) polymorphisms and uterine myomas by Ahmadi, for MSc degree in Molecular Genetics.

\section{Footnotes}

Authors' Contribution: Ahmad Ebrahimi, study concept and design and administrative support; Marzieh Ahmadi, technical and material support and preparing the first draft of the manuscript; Mahboobeh Nasiri, interpretation of the data, critical revision of the manuscript for important intellectual content, statistical analyses and study supervision.

Conflict of Interest: None declared.

Funding/Support: This study was supported by Islamic Azad University, Arsanjan Branch.

\section{References}

1. Neiger R, Sonek JD, Croom CS, Ventolini G. Pregnancy-related changes in the size of uterine leiomyomas. J Reprod Med. 2006;51(9):671-4. [PubMed: 17039693].

2. Ruf W. Tissue factor and cancer. Thromb Res. 2012;130 Suppl 1:S84-7. doi: 10.1016/j.thromres.2012.08.285. [PubMed: 23026674].

3. Trikha M, Nakada MT. Platelets and cancer: implications for antiangiogenic therapy. Semin Thromb Hemost. 2002;28(1):39-44. doi: 10.1055/s-2002-20563. [PubMed: 11885024].

4. Vairaktaris E, Yapijakis C, Wiltfang J, Ries J, Vylliotis A, Derka S, et al. Are factor $\mathrm{V}$ and prothrombin mutations associated with increased risk of oral cancer?. Anticancer Res. 2005;25(3c):2561-5. [PubMed: 16080493].

5. Palla A, Celi A, Marconi L, Pistelli F, Tavanti L, Desideri M, et al. Venous Thromboembolism in Cancer: Frequently Asked Questions When Guidelines are Inconclusive. Cancer Invest. 2015;33(4):142-51. doi: 10.3109/07357907.2015.1009631. [PubMed: 25781145].

6. Kitajima T, Hatano E, Mitsunori Y, Taura K, Fujimoto Y, Mizumoto M, et al. Complete pathological response induced by sorafenib for advanced hepatocellular carcinoma with multiple lung metastases and venous tumor thrombosis allowing for curative resection. Clin J Gastroenterol. 2015;8(5):300-5. doi: 10.1007/s12328-015-0594-7. [PubMed: 26249525].
7. Haynes MC, Lu BY, Winkel AF. Ovarian vein thrombophlebitis related to large uterine myoma. Obstet Gynecol. 2014;123(2 Pt 2 Suppl 2):450-3. doi: 10.1097/AOG.0000000000000091. [PubMed: 24413242].

8. Wu CJ, Huang $\mathrm{KH}$, Liu JY. Ovarian vein thrombosis associated with compression by a uterine myoma. Eur J Obstet Gynecol Reprod Biol. 2011;159(2):485-7. doi: 10.1016/j.ejogrb.2011.09.037. [PubMed: 22018915].

9. Board PG, Chapple R, Coggan M. Haplotypes of the coagulation factor XIII A subunit locus in normal and deficient subjects. Am J Hum Genet. 1988;42(5):712-7. [PubMed: 2895980].

10. Coggan M, Baker R, Miloszewski K, Woodfield G, Board P. Mutations causing coagulation factor XIII subunit A deficiency: characterization of the mutant proteins after expression in yeast. Blood. 1995;85(9):2455-60. [PubMed: 7727776].

11. Morelli VM, De Visser MC, Vos HL, Bertina RM, Rosendaal FR. ABO blood group genotypes and the risk of venous thrombosis: effect of factor V Leiden. J Thromb Haemost. 2005;3(1):183-5. doi: 10.1111/j.15387836.2004.01071.x. [PubMed: 15634288].

12. Ichinose A, Davie EW. Characterization of the gene for the a subunit of human factor XIII (plasma transglutaminase), a blood coagulation factor. Proc Natl Acad Sci US A. 1988;85(16):5829-33. [PubMed: 2901091].

13. Ariens RA, Philippou H, Nagaswami C, Weisel JW, Lane DA, Grant PJ. The factor XIII V34L polymorphism accelerates thrombin activation of factor XIII and affects cross-linked fibrin structure. Blood. 2000;96(3):988-95. [PubMed: 10910914].

14. Nadir Y, Brenner B, Gingis-Velitski S, Levy-Adam F, Ilan N, Zcharia $\mathrm{E}$, et al. Heparanase induces tissue factor pathway inhibitor expression and extracellular accumulation in endothelial and tumor cells. Thromb Haemost. 2008;99(1):133-41. [PubMed: 18217145].

15. Van Hylckama Vlieg A, Komanasin N, Ariens RA, Poort SR, Grant PI, Bertina RM, et al. Factor XIII Val34Leu polymorphism, factor XIII antigen levels and activity and the risk of deep venous thrombosis. $\mathrm{Br} \mathrm{J}$ Haematol. 2002;119(1):169-75. [PubMed: 12358922].

16. Cripe LD, Moore KD, Kane WH. Structure of the gene for human coagulation factor V. Biochemistry. 1992;31(15):3777-85. [PubMed: 1567832].

17. Palumbo JS, Talmage KE, Massari JV, La Jeunesse CM, Flick MJ, Kombrinck KW, et al. Platelets and fibrin(ogen) increase metastatic potential by impeding natural killer cell-mediated elimination of tumor cells. Blood. 2005;105(1):178-85. doi: 10.1182/blood-2004-06-2272. [PubMed: 15367435].

18. Parker WH. Etiology, symptomatology, and diagnosis of uterine myomas. Fertil Steril. 2007;87(4):725-36. doi: 10.1016/j.fertnstert.2007.01.093. [PubMed:17430732].

19. Longmire JL, Albright KL, Lewis AK, Meincke LJ, Hildebrand CE. A rapid and simple method for the isolation of high molecular weight cellular and chromosome-specific DNA in solution without the use of organic solvents. Nucleic Acids Res. 1987;15(2):859. [PubMed: 3822818].

20. Vairaktaris E, Vassiliou S, Yapijakis C, Spyridonidou S, Vylliotis A, Derka $S$, et al. Increased risk for oral cancer is associated with coagulation factor XIII but not with factor XII. Oncol Rep. 2007;18(6):1537-43. [PubMed: 17982641].

21. Boccaccio C, Sabatino G, Medico E, Girolami F, Follenzi A, Reato G, et al. The MET oncogene drives a genetic programme linking cancer to haemostasis. Nature. 2005;434(7031):396-400. doi: 10.1038/nature03357. [PubMed: 15772665].

22. Hodge JC, Morton CC. Genetic heterogeneity among uterine leiomyomata: insights into malignant progression. Hum Mol Genet. 2007;16 Spec No 1:R7-13. doi: 10.1093/hmg/ddm043. [PubMed: 17613550].

23. Dehraisi M, Sadat S, Sadat SM, Davari Tanha F, Aghasadeghi M, Bahramali $\mathrm{G}$, et al. The effect of glutathione S-transferase gene polymorphisms on susceptibility to uterine myoma. Tehran Univ Med J. 2015;72(10):667-73.

24. Taghizade Mortezaee F, Hashemzadeh Chaleshtori M, Kheiri S, Farrokhi E, Shariati L, Tabatabaiefar MA. Interleukin-1b gene polymorphisms in iranian patients with uterine fibroid, A case- control study. Biosci Biotech Res Asia. 2015;12(1):341-5. 
25. Salimi S, Mohammadoo-Khorasani M, Namazi L, Naghavi A, Yaghmaei M. Association between interleukin 4 gene seventy-base-pair variable number of tandem repeats polymorphism and uterine leiomyoma. Gene, Cell and Tissue. 2014;1(2).

26. Wang F, Chen J, Wang L, Ma Y, Mayinuer N. CYP1A1 genetic polymorphisms and uterine leiomyoma risk: a meta-analysis. IntJClin Exp Med. 2015;8(3):3590-4. [PubMed: 26064254].

27. Mu X, Du X, Yao K, Zhao J, Bian C, Wang Q, et al. Association between HSD17B1 rs605059 polymorphisms and the risk of uterine diseases: a systemic review and meta-analysis. Int J Clin Exp Pathol. 2015;8(6):6012-8. [PubMed: 26261478].

28. Falanga A, Marchetti M, Vignoli A. Coagulation and cancer: biological and clinical aspects. J Thromb Haemost. 2013;11(2):223-33. doi: 10.1111/jth.12075. [PubMed: 23279708].

29. Fernandes F, Dinardo C, Terra-Filho M. Uterine myoma as a cause of iliac vein thrombosis and pulmonary embolism: common disease, rare complication. Respirology Case Reports. 2014;2(4):132-4.

30. Hoh JK, Lee WM, Lee HJ, Hwang JH. Misdiagnosis of a large uterine vein thrombosis as a uterine myoma prior to hysterectomy: a case report. Ann Acad Med Singapore. 2013;42(2):88-90. [PubMed: 23515692].

31. van der Meijden PE, Heemskerk JW. Polyphosphates: a link between platelet activation, intrinsic coagulation and inflammation?. Expert Rev Hematol. 2010;3(3):269-72. doi: 10.1586/ehm.10.26. [PubMed: 21082980].

32. van Wijk R, Nieuwenhuis K, van den Berg M, Huizinga EG, van der Meijden BB, Kraaijenhagen RJ, et al. Five novel mutations in the gene for human blood coagulation factor V associated with type I factor V deficiency. Blood. 2001;98(2):358-67. [PubMed:11435304].

33. Franco RF, Reitsma PH, Lourenco D, Maffei FH, Morelli V, Tavella MH, et al. Factor XIII Val34Leu is a genetic factor involved in the etiology of venous thrombosis. Thromb Haemost. 1999;81(5):676-9. [PubMed: 10365735].

34. Corapcioglu F, Basar EZ, Demirel A, Inan N, Babaoglu K, Karakurt H et al. Granulomatous reaction in mediastinal B-cell non-Hodgkin lymphoma and intracardiac thrombosis. Pediatr Hematol Oncol. 2008;25(3):217-26. doi: 10.1080/08880010701884675. [PubMed: 18432505].

35. Vossen CY, Hoffmeister M, Chang-Claude JC, Rosendaal FR, Brenner $\mathrm{H}$. Clotting factor gene polymorphisms and colorectal cancer risk. $J$ Clin Oncol. 2011;29(13):1722-7. doi: 10.1200/JCO.2010.31.8873. [PubMed: 21422408]. 